\title{
Liquid Membrane Technology-Extraction and Carrier Facilitated Transport of Some Metal Ions Using Noncyclic Ionophores
}

\author{
Shipra Khamaru, Nidhi Joshi, Anubhuti Awasthy And Uma Sharma* \\ School of Studies in Chemistry, Vikram University Ujjain (M.P.), 456010 \\ umasharma10@rediffmail.com
}

\begin{abstract}
The extraction and carrier facilitated transport of $\mathrm{Mg}^{++}, \mathrm{Ca}^{++}, \mathrm{Na}^{+}$and $\mathrm{K}^{+}$has been studied using a series of non-cyclic ionophores through chloroform bulk liquid membrane system. The ionophores used were viz. DEGDBE (I), DEGDB (II) 0,O,O'Oxydiethyline diglycolic acid (III) and O,O,O'Oxydiethyline diglycolic mono acetate(IV). The amount of metal ions extracted as well as transported mainly depends upon the structure of the ionophore, its concentration and also on the concentration of metal ions.
\end{abstract}

\section{INTRODUCTION}

Molecule recognition is a central point. It may be said that without molecular recognition there would be no life in this world $/ 1 \%$ Vital biochemical processes such as enzyme action, molecular transport genetic information, processing and protein assembly all involve molecular recognition as an essential action. It was Paul Enrich who recognized the molecular rule: they do not act if they do not bind. Thus, introduction of the concept of receptors mainly depends upon the interaction binding.

Supramolecular species and assemblies are held together and organized by means of non-covalent interaction. It is a highly interdisciplinary field of science and technology. Owing to the interdisciplinary nature of the subject, interest grew very fast. The design of ionophores and their ability to bind, recognize and transport cations through membranes is an interesting subject with important application in several areas, as in ion selective electrodes, sensors with analytical uses $/ 2 /$.

\section{EXPERIMENTAL}

The ionophores used are:

Diethylene glycol dibutylether. DEBDBE (I) 
Diethylene glycol dibenzoate. DEGDB (II)

O,O,O'Oxydiethylene diglycolic acid(III)

O,O,O'Oxydiethylene diglycolic mono acetate(IV)

For structures see Scheme 1.

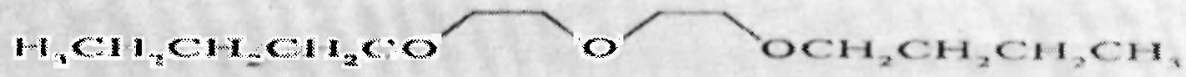

$18 \times C=131 \times 18$

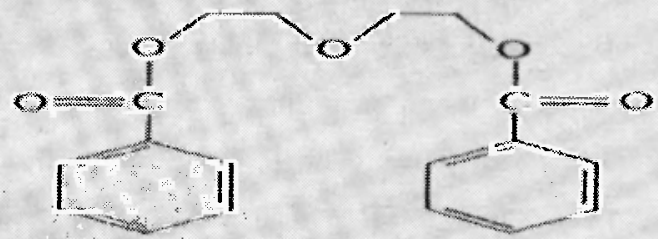

O $60 \%$
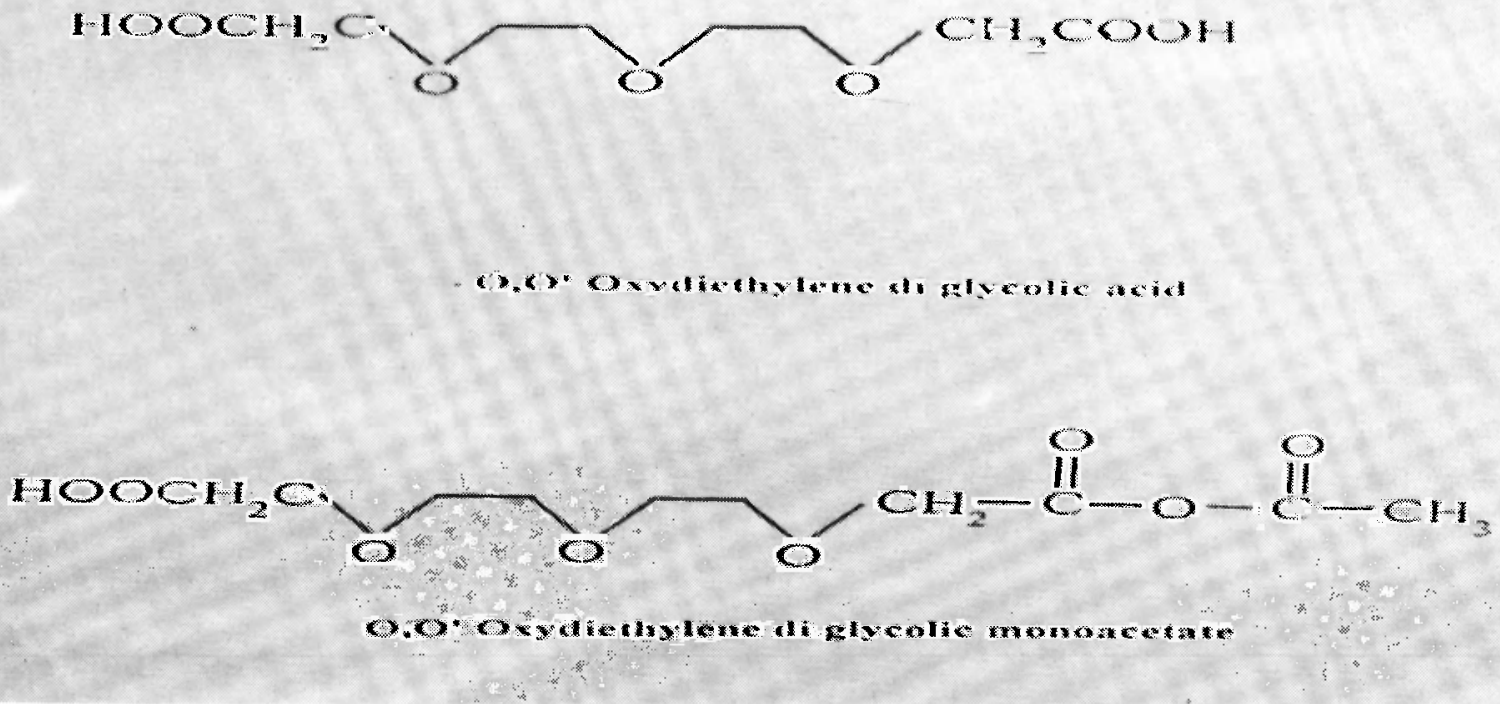

Scheme 1

Ionophores used in the present studies

Diethylene glycol dibutylether (DEGDBE), Diethylene glycol dibenzoate (DEGDB) were obtained from Aldrich and used as such. Ionophores (I)\&(II) synthesised in our laboratory were the same as reported $/ 2 /$. Alkali and alkaline earth metal picrates (MPic), dinitrophenolates (MDnp), orthonitrophenolates (MOnp) were prepared as reported earlier $/ 4 /$. 
Extraction studies (for apparatus, see Fig. 1).

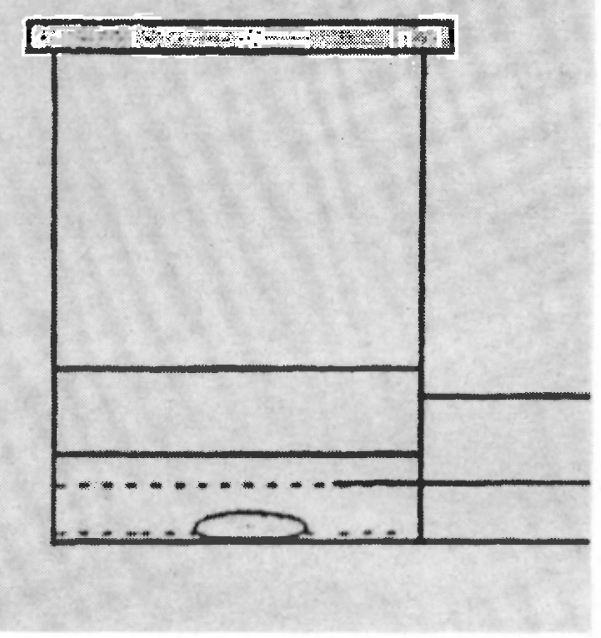

Source phase

Organic phase (ionophore solution)

Teflon coated capsule $=$ magnetic stirrer

Fig. 1: Apparatus for extraction studies

For extraction $/ 5 /, 10 \mathrm{ml}$ of $1 \times 10^{-3} \mathrm{M}$ aqueous metal salt solution was vigorously stirred with $10 \mathrm{ml}$ of $1 \times 10^{-3} \mathrm{M}$ Ionophore solution in an organic solvent $\left(\mathrm{CHCl}_{3}\right)$ in a small beaker using a magnetic stirrer (100rpm). The beaker was covered and kept in a thermostated incubator. The amount of cation in aqueous phase was initially determined. After 5 hour stirring, the mixture was allowed to stand for $5 \mathrm{~min}$. for the separation of two phases, The depleted aqueous phase was removed and analyzed for metal using Systronics Flame photometer. The amount of metal cation extracted by the ionophore was found by determining its difference in aqueous phase before and after extraction. Values of distribution ratio $D_{M}$ were calculated as follows $/ 6 /$ :

$$
D_{M}=\frac{\text { Total Cone. of Metal Cation in Organic Phase }}{\text { Total Conc. of Metal Cation in Aqueous Phase }}
$$

\section{Transport Studies (for apparatus see Fig. 2)}

Transport experiments were performed in a U-tube glass cell $/ 7 /$, placed in a thermostats incubator $(250 \pm$ $10^{\circ} \mathrm{C}$ ), the $1 \times 10^{-3} \mathrm{M}$ carrier in $25 \mathrm{ml}$ of organic solvent was placed in the bottom of the U-tube serving as the membrane. $10 \mathrm{ml}$ of $1 \times 10^{-3} \mathrm{M}$ of aqueous solution of metal cation was placed in one limb of the U-tube, serving as source phase and $10 \mathrm{ml}$ of double-distilled water was placed in the other limb of the U-tube, which served as the receiving phase. The two aqueous phases, i.e. source and receiving phase, floated on the organic membrane phase respectively in two limbs. The membrane phase was constantly stirred, using a magnetic stirrer $(100 \mathrm{rpm})$. The samples were withdrawn from source and receiving phase after 24 hours and analyzed for cation transported, using flame photomety. Cation flux values were calculated by using the relation $/ 2 /$ : 


$$
\mathrm{J}_{\mathrm{M}}=\frac{\mathrm{C} \text { (receiving) } \mathrm{V}}{(\mathrm{At})}
$$

where

$C$ is the concentration of cation in receiving phase $-\mathrm{mol} / \mathrm{dm}^{3}$

$\mathrm{V}$ is the volume of receiving phase $-\mathrm{dm}^{3}$

$A$ is the effective area of membrane $-\mathrm{m}^{2}$

$t$ is the time -sec

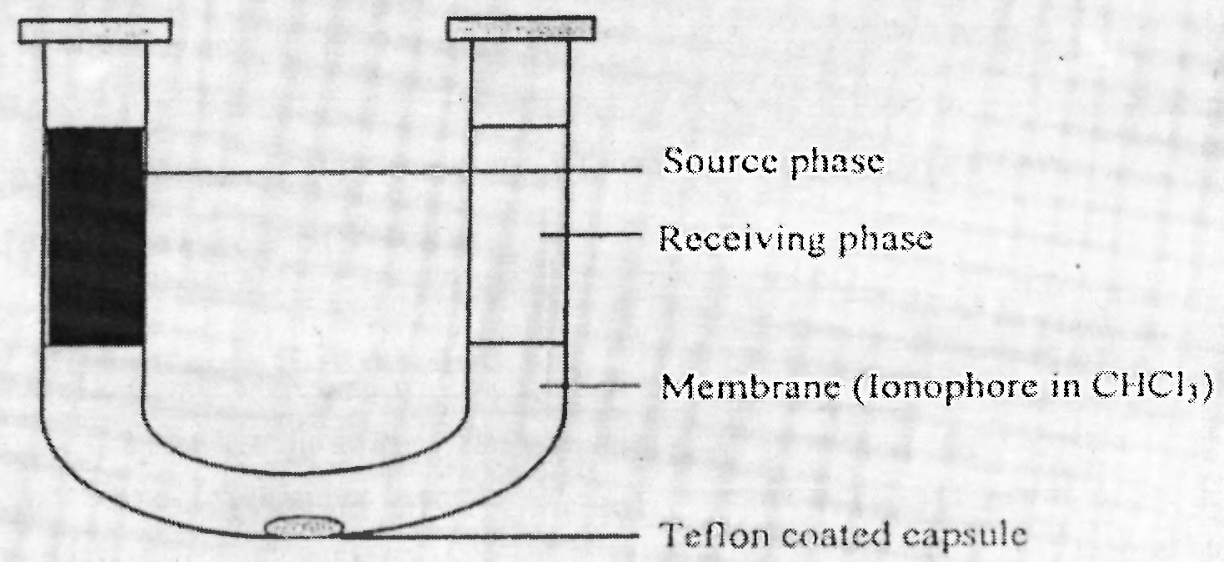

Fig. 2: U tube cell for BLM transport studies

\section{RESULTS AND DISCUSSION}

A blank experiment was carried out for extraction and transport studies for each salt, in which membrane was devoid of carrier. No leakage of cation from source into organic phase was observed. All measurements were performed in triplicate. The results of extraction and transport studies are listed in Tables (I-IV).

The amount of metal cations extracted as well as transported mainly depends upon the structure of the ionophores. The ionophores (I-IV) used in this study are podands having different end groups and chain lengths. Among all four ionophores studied. Ionophores I and II show the best carrier ability for alkali metal cations while ionophores III and IV show it for alkaline earth metal cations.

Ionophores I and II have small chain lengths; ionophore I has a less flexible end group and ionophore II has a rigid aromatic end group, The results of extraction studies indicate that generally $\mathrm{K}^{+}$is more efficiently extracted into the organic phase than $\mathrm{Na}^{+}$; this is because $\mathrm{K}^{+}$is a less solvated ion; therefore it can be readily 
extracted by ionophores in the organic phase. In transport studies $\mathrm{Na}^{+}$, which is a highly solvated ion, tends to remain in the source phase.

Table 1

Amount of $\mathrm{Na}^{+}, \mathrm{K}^{+}, \mathrm{Mg}^{++}, \mathrm{Ca}^{++}$cations extracted and transported into an organic phase after $24 \mathrm{~h}$ with diethylene glycol dibutylether in chloroform.

\begin{tabular}{|c|c|c|c|c|c|c|}
\hline S.No. & Metal Salts & $\begin{array}{c}\text { Cation } \\
\text { extracted } \\
(\mathbf{p p m})\end{array}$ & $\begin{array}{c}\text { Cation } \\
\text { transported } \\
(\mathrm{ppm})\end{array}$ & Metal Salts & $\begin{array}{c}\text { Cation } \\
\text { extracted } \\
(\mathbf{p p m})\end{array}$ & $\begin{array}{c}\text { Cation } \\
\text { transported } \\
(\mathbf{p p m})\end{array}$ \\
\hline 1 & $\mathrm{NaPic}$ & 0.23 & 10.87 & $\mathrm{CaPic}$ & - & 0.45 \\
\hline 2 & $\mathrm{NaDnp}$ & 0.10 & 6.52 & $\mathrm{Ca} \mathrm{Dnp}$ & - & - \\
\hline 3 & $\mathrm{NaOnp}$ & 0.11 & 6.52 & $\mathrm{Ca}$ Onp & - & - \\
\hline 4 & $\mathrm{NaSCN}$ & 7.50 & - & - & - & - \\
\hline 5 & $\mathrm{Kpic}$ & 0.14 & 0.19 & $\mathrm{Mg}$ Pic & - & - \\
\hline 6 & $\mathrm{KDnp}$ & 15.0 & 0.13 & $\mathrm{Mg}$ Dnp & - & - \\
\hline 7 & $\mathrm{Konp}$ & 0.12 & 0.13 & $\mathrm{MgOnp}$ & - & - \\
\hline 8 & $\mathrm{KSCN}$ & - & - & - & - & - \\
\hline
\end{tabular}

Table 2

Amount of $\mathrm{Na}^{+}, \mathrm{K}^{+}, \mathrm{Mg}^{++}, \mathrm{Ca}^{++}$cations extracted and transported into an organic phase in $24 \mathrm{~h}$ with diethylene glycol dibenzoate in chloroform

\begin{tabular}{|c|c|c|c|c|c|c|}
\hline S.No. & Metal Salts & $\begin{array}{c}\text { Cation } \\
\text { extracted } \\
(\mathbf{p p m})\end{array}$ & $\begin{array}{c}\text { Cation } \\
\text { transported } \\
(\mathbf{p p m})\end{array}$ & Metal Salts & $\begin{array}{c}\text { Cation } \\
\text { extracted } \\
(\mathbf{p p m})\end{array}$ & $\begin{array}{c}\text { Cation } \\
\text { transported } \\
(\mathbf{p p m})\end{array}$ \\
\hline 1 & NaPic & 15.0 & 2.00 & CaPic & 03 & 01 \\
\hline 2 & NaDnp & - & 0.80 & $\mathrm{Ca} \mathrm{Dnp}$ & - & - \\
\hline 3 & $\mathrm{NaOnp}$ & - & 1.60 & $\mathrm{Ca}$ Onp & - & - \\
\hline 4 & $\mathrm{NaSCN}$ & 08 & - & - & - & - \\
\hline 5 & $\mathrm{Kpic}$ & 15.0 & 1.50 & $\mathrm{Mg}$ Pic & - & - \\
\hline 6 & $\mathrm{KDnp}$ & 25.0 & 0.20 & $\mathrm{Mg} \mathrm{Dnp}$ & - & - \\
\hline 7 & $\mathrm{Konp}$ & 30.0 & 0.60 & $\mathrm{MgOnp}$ & - & - \\
\hline 8 & $\mathrm{KSCN}$ & 20.0 & 0.10 & - & - & - \\
\hline
\end{tabular}


Table 3

Amount of $\mathrm{Na}^{+}, \mathrm{K}^{+}, \mathrm{Mg}^{+}, \mathrm{Ca}^{++}$cations extracted and transported into an organic phase $24 \mathrm{~h}$ with $\mathrm{O}, \mathrm{O}$ oxydiethylene diglycolic acid in chloroform

\begin{tabular}{|c|c|c|c|c|c|c|}
\hline S.No. & Metal Salts & $\begin{array}{c}\text { Cation } \\
\text { extracted } \\
(\mathbf{p p m})\end{array}$ & $\begin{array}{c}\text { Cation } \\
\text { transported } \\
(\mathbf{p p m})\end{array}$ & Metal Salts & $\begin{array}{c}\text { Cation } \\
\text { extracted } \\
\text { (ppm) }\end{array}$ & $\begin{array}{c}\text { Cation } \\
\text { transported } \\
\text { (ppm) }\end{array}$ \\
\hline 1 & NaPic & 10 & & CaPic & 06 & 25 \\
\hline 2 & NaDnp & - & & Ca Dnp & - & 44 \\
\hline 3 & NaOnp & - & & Ca Onp & - & 33 \\
\hline 4 & NaSCN & 30 & & - & & \\
\hline 5 & Kpic & - & & Mg Pic & 03 & 13 \\
\hline 6 & KDnp & - & & Mg Dnp & - & 31 \\
\hline 7 & Konp & - & & MgOnp & - & 28 \\
\hline 8 & KSCN & 02 & & - & & \\
\hline
\end{tabular}

Table 4

Amount of $\mathrm{Na}^{+}, \mathrm{K}^{+}, \mathrm{Mg}^{++}, \mathrm{Ca}^{++}$cations extracted and transported into an organic phase in $24 \mathrm{~h}$ with $\mathrm{O}, \mathrm{O}$ oxydiethylene diglycolic monoacetate in chloroform.

\begin{tabular}{|c|c|c|c|c|c|c|}
\hline S.No. & Metal Salts & $\begin{array}{c}\text { Cation } \\
\text { extracted } \\
(\mathbf{p p m})\end{array}$ & $\begin{array}{c}\text { Cation } \\
\text { transported } \\
(\mathbf{p p m})\end{array}$ & Metal Salts & $\begin{array}{c}\text { Cation } \\
\text { extracted } \\
\text { (ppm) }\end{array}$ & $\begin{array}{c}\text { Cation } \\
\text { transported } \\
\text { (ppm) }\end{array}$ \\
\hline 1 & $\mathrm{NaPic}$ & 20 & 1.0 & $\mathrm{CaPic}$ & 03 & 63 \\
\hline 2 & $\mathrm{NaDnp}$ & - & - & $\mathrm{Ca}$ Dnp & - & 80 \\
\hline 3 & $\mathrm{NaOnp}$ & - & - & $\mathrm{Ca}$ Onp & - & 79 \\
\hline 4 & $\mathrm{NaSCN}$ & 20 & 1.0 & - & & \\
\hline 5 & $\mathrm{Kpic}$ & - & 0.5 & $\mathrm{Mg}$ Pic & 02 & 57 \\
\hline 6 & $\mathrm{KDnp}$ & - & - & $\mathrm{Mg}$ Dnp & - & 15 \\
\hline 7 & $\mathrm{Konp}$ & - & - & $\mathrm{MgOnp}$ & - & 14 \\
\hline 8 & $\mathrm{KSCN}$ & 220 & 04 & - & & \\
\hline
\end{tabular}

There is an inverse relation between extraction and transport processes, as uptake of molecules is important for extraction while release of molecule is important for transport (Fig. 3). 


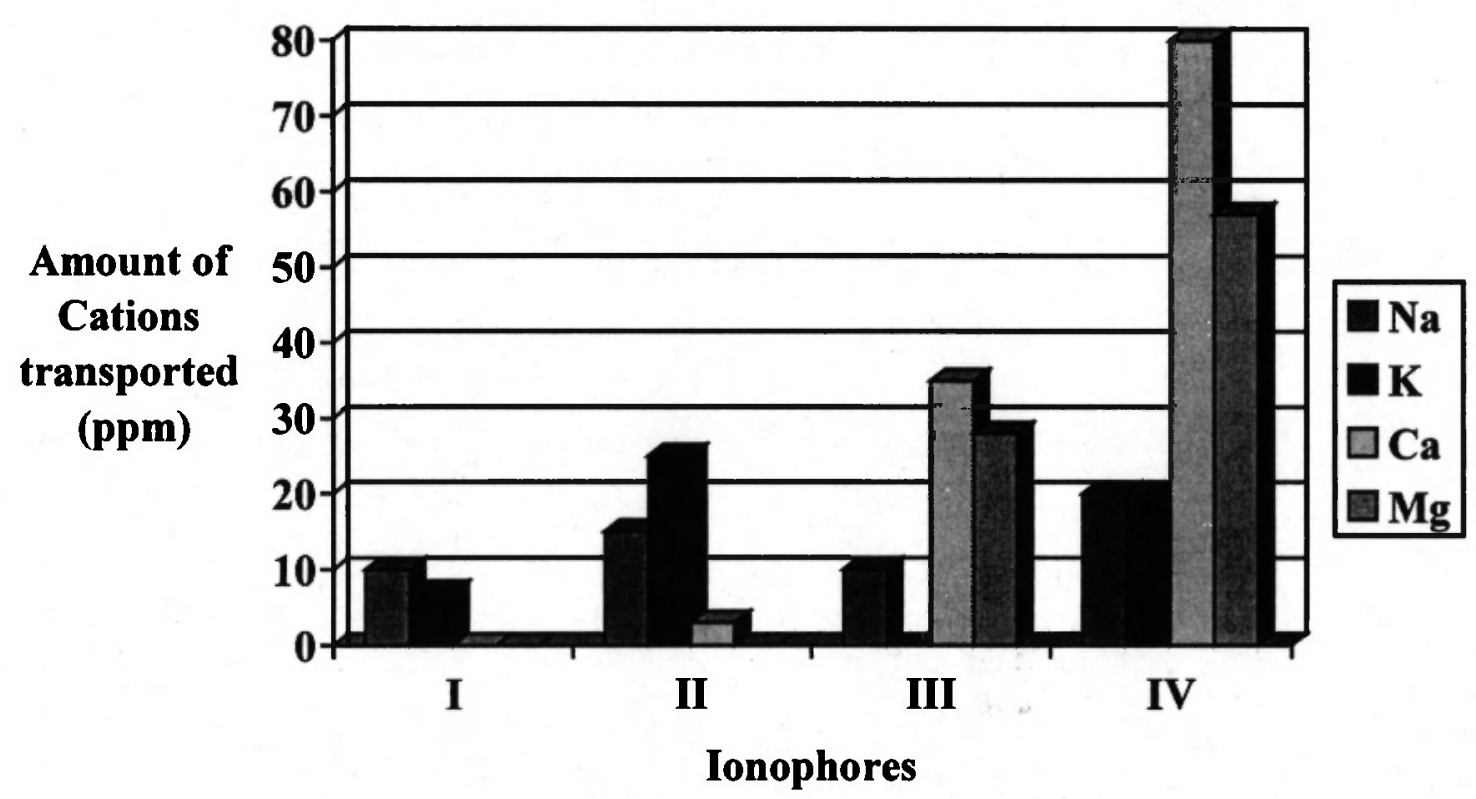

Fig. 3: Amount of Metal Cations Transported with Ionophores

Ionophores III and IV, having long chain lengths and flexible double-action /3/ end group and flexible conformation, show higher transport values of alkaline earth metal cations. Higher extraction with thiocyanates can be explained on the basis of double action end group, co-ordinating to the cation and simultaneously stabilising the anion by hydrogen bonding.

Maximum transport rate (Fig 3) was observed when the counter anion was picrate. The charge on the picrate anion is more delocalized than dnp- and onp- and hence less associated with the cation.

\section{ACKNOWLEDGEMENT}

Finally, assistance from the Council of Scientific Industrial Research, New Delhi is gratefully acknowledged.

\section{REFERENCES}

1. J.C. Medina, I. Gay, Z. Chenz, J.Am.Chem.Soc., 113, 365-366 (1991).

2. M. Bhatnagar and U. Sharma, J.Sci.Islamic.Rep.Iran, 13 (2), 113-120 (2002).

3. N.S. Poonia, A.V. Bajaj, Chem.Rev., 79, 389 (1979).

4. H.M. Burger, D. Seebach, Helv.Chim.Acta, 76, 2570 (1993).

5. W. Walkowiak, D.H. Desai and R.A. Bartsch, Anal.Chem., 64, 1685 (1992). 
6. D. Mishra, S. Deepa, U. Sharma, Sep.Sci.andTechnol, 34 (15), 3113 (1999).

7. J.P. Shukla and S.K. Mishra, J. Memb.Sci., 64, 93 (1999). 